\title{
Unprecedented $\eta^{3}$-Coordination and Functionalization of the 2- Phosphaethynthiolate Anion at Lanthanum(III)
}

\author{
Fabian A. Watt, ${ }^{[b]}$ Lukas Burkhardt, ${ }^{[b]}$ Roland Schoch, ${ }^{[b]}$ Stefan Mitzinger, ${ }^{[c]}$ Matthias Bauer, ${ }^{[b]}$ Florian \\ Weigend, ${ }^{[\mathrm{d}] *}$ Jose M. Goicoechea, ${ }^{[\mathrm{c}] *}$ Frank Tambornino, ${ }^{[\mathrm{d}] *}$ and Stephan Hohloch ${ }^{[\mathrm{a}] *}$
}

In memory of Prof. Dr. G. Becker on the occasion of his 80th birthday.

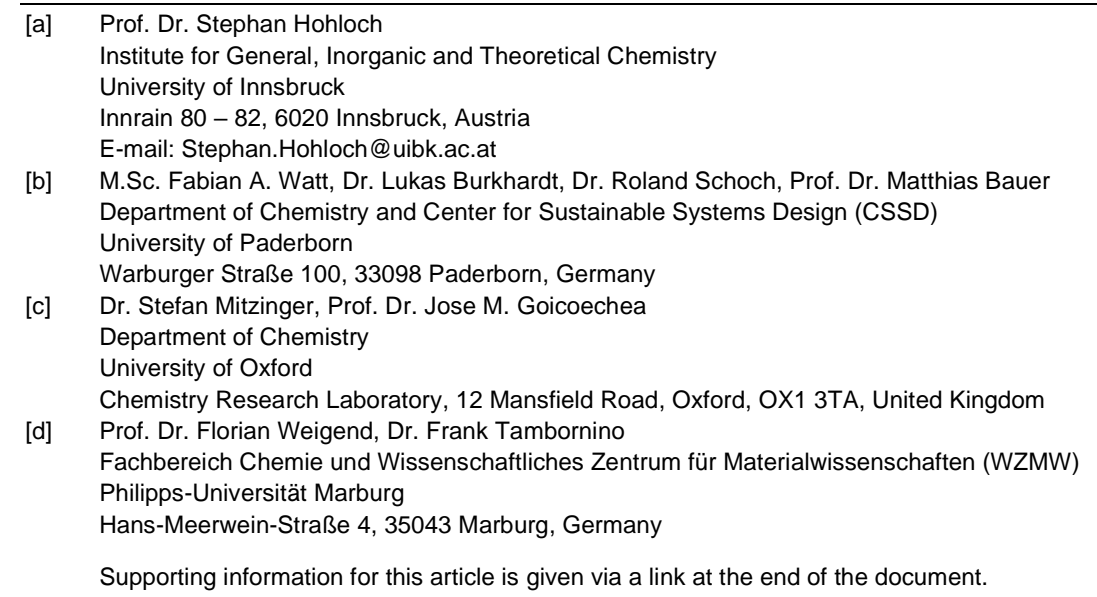

\begin{abstract}
We present the unprecedented $\eta^{3}$-coordination of the 2phosphaethynthiolate anion in the complex $(\mathrm{PN})_{2} \mathrm{La}(\mathrm{SCP})$ (2) [PN = $\mathrm{N}$-(2-(diisopropylphosphanyl)-4-methylphenyl)-2,4,6-trimethylanilide)] Structural comparison with dinuclear thiocyanate bridged $(\mathrm{PN})_{2} \mathrm{La}(\mu-$ 1,3-SCN $)_{2} \mathrm{La}(\mathrm{PN})_{2}(3)$ and azide bridged $(\mathrm{PN})_{2} \mathrm{La}\left(\mu-1,3-\mathrm{N}_{3}\right)_{2} \mathrm{La}(\mathrm{PN})_{2}$ (4) complexes indicates that the [SCP] $]^{-}$coordination mode is mainly governed by electronic, rather than steric factors. Quantum mechanical investigations reveal large contributions of the antibonding $\pi$-orbital of the [SCP]- ligand to the LUMO of complex $\mathbf{2}$, rendering it the ideal precursor for the first functionalization of the $\left.{ }^{[S C P}\right]^{-}$anion. Complex 2 was therefore reacted with CAACs which induced a selective rearrangement of the [SCP] $]^{-}$ligand to form the first CAAC stabilized group 15 - group 16 fulminate-type complexes $(\mathrm{PN})_{2} \mathrm{La}\left\{\mathrm{SPC}\left({ }^{\mathrm{R} C A A C}\right)\right\} \quad(\mathbf{5 a}, \mathbf{b}) \quad(\mathrm{R}=\mathrm{Ad}, \mathrm{Me})$. A detailed reaction mechanism for the SCP to SPC isomerization is proposed based on DFT calculations.
\end{abstract}

\section{Introduction}

The (coordination) chemistry of the 2-phosphaethynolate $\left([\mathrm{OCP}]^{-}\right)$anion continues to be a vibrant, highly topical research field in the chemical sciences ${ }^{[1]}$ and has already led to the isolation of a plethora of novel or rare phosphorus-containing heterocycles, ${ }^{[2]}$ the first stable singlet phosphinidene, ${ }^{[3]}$ as well as many (functional) coordination compounds covering the whole periodic table ${ }^{[1],[4]}$ - from main group elements ${ }^{[5,6]}$ and transition metals $^{[7]}$ to the lanthanides ${ }^{[8]}$ and actinides. ${ }^{[9]}$ In contrast, the chemistry of the heavier analogues, e.g. the 2phosphaethynthiolate $\left([\mathrm{SCP}]^{-}\right)$anion, has been much less developed so far, although both the $[\mathrm{OCP}]^{-[10]}$ and the $[\mathrm{SCP}]^{-}$ anion $^{[11]}$ were first reported in the 1990 s by Becker and coworkers as their lithium salts. This can partly be attributed to the notorious instability of $\mathrm{Li}(\mathrm{DME})_{3} \mathrm{SCP}$ (similar to $\left.\mathrm{Li}(\mathrm{DME})_{2} \mathrm{OCP}\right) .{ }^{[1]}$ However, even after establishing high-yielding routes to long-term stable (room temperature and moderately air tolerant) sodium or potassium salts of both [SCP] $]^{-}$and [OCP] $]^{-[12],[13]}$ the chemistry of the former remains largely dormant. To date, apart from electrochemical and spectroscopic investigations, ${ }^{[14]}$ only one $[\mathrm{SCP}]^{-}$coordination compound in the form of $[\mathrm{K}(18$-crown6)] $\left[\mathrm{W}(\mathrm{CO})_{5}(\mathrm{SCP})\right]$ has been reported. ${ }^{[12]}$ This first example demonstrated the potential difficulties to be encountered in [SCP]coordination chemistry: Due to the unusually high negative charge density on the central carbon atom of the [SCP]- anion (natural bond orbital atomic charges correspond to -0.28 for $S$, 0.74 for $\mathrm{C}$ and 0.03 for $\mathrm{P}),{ }^{[13]}$ only a mixture of $\mathrm{S}$ - and $\mathrm{P}$-bound isomers could be obtained, which decomposed at room temperature within four days.

We have recently begun to investigate the chemistry of anilidophosphine-supported lanthanum(III) complexes of the general formula $(\mathrm{PN})_{2} \mathrm{LaX}$ with $\mathrm{X}=\mathrm{Cl}(\mathbf{1}-\mathrm{Cl})$ and I (1-I), ${ }^{[15]}$ and have shown them to be versatile precursors for the synthesis of pentacoordinate lanthanum(III) primary phosphido and sulfido complexes $(\mathrm{PN})_{2} \mathrm{La}(\mathrm{EMes})(\mathrm{E}=\mathrm{PH}, \mathrm{S})$. Due to the insertion reactivity of the La-P phosphide bond, the former allowed us to construct phosphaureate and phosphathioureate ligands, which can be used to build unprecedented heterobimetallic systems. ${ }^{[16]}$ Furthermore, the same phosphido complex led us to study the reactivity of a transient (terminal) phosphinidene complex. ${ }^{[17]}$ Acknowledging that the use of a neutral metal atom such as tungsten(0) did not favor a defined coordination of the [SCP] ${ }^{-}$ anion and considering the high utility of our anilidophosphinesupported lanthanum(III) framework to obtain relatively stable, yet still potentially reactive La-P and La-S bonds, we envisioned that the use of a highly electropositive and Lewis-acidic metal ion such as lanthanum(III) might alter the charge distribution of the [SCP] 
anion sufficiently to give access to a defined S- or P-bound version and to study its chemistry in more detail.

\section{Results and Discussion}

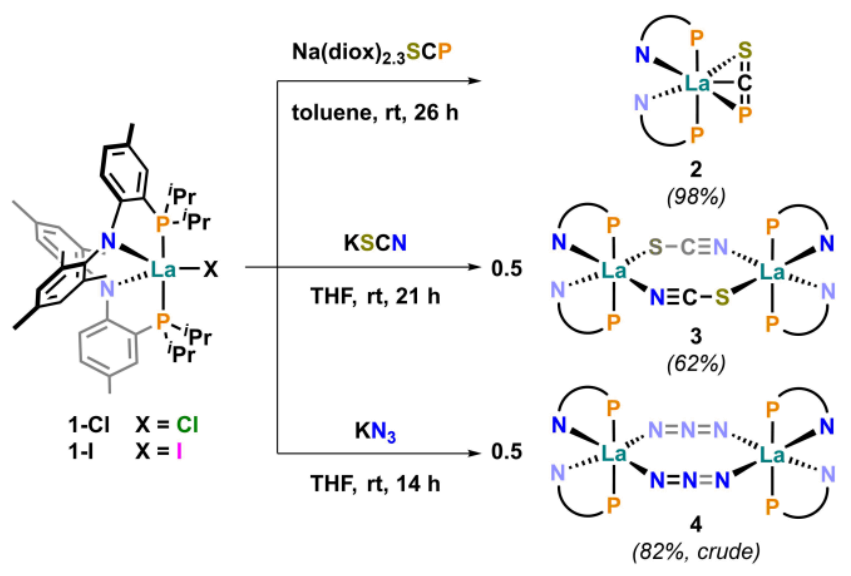

Scheme 1. Syntheses of Complexes 2-4, Starting from 1-X.

Starting from either $\mathbf{1 - C l}$ or $\mathbf{1 - I}$, salt metathesis reaction with an excess of $\mathrm{Na}$ (diox) 2.3 $_{3} \mathrm{SCP}$ (1.4 equiv) in toluene was found to take place at room temperature and to result in the formation of a single new product 2 overnight (Scheme 1). This was evident by the darkening of the initially pale yellow suspension and the ${ }^{31} \mathrm{P}\left\{{ }^{1} \mathrm{H}\right\}$ NMR spectrum of the reaction mixture, showing a new singlet at $\delta=-44.9 \mathrm{ppm}$ which was assigned to the $[S C P]^{-}$ phosphorus atom. After filtration, removal of toluene in vacuo and trituration with $n$-pentane, 2 was obtained as an amber solid in $98 \%$ isolated yield. In the ${ }^{13} \mathrm{C}\left\{{ }^{1} \mathrm{H}\right\}$ NMR spectrum $\left(\mathrm{C}_{6} \mathrm{D}_{6}\right)$ of the isolated material a doublet at $\delta=191.8 \mathrm{ppm}\left({ }^{1} J_{\mathrm{CP}}=20.6 \mathrm{~Hz}\right)$, corresponding to the $[\mathrm{SCP}]^{-}$carbon atom, ${ }^{[13]}$ strongly suggested a defined coordination of the $[\mathrm{SCP}]^{-}$anion. Additionally, sharp signals indicated little to no rearrangement on the NMR timescale. Notably, 2 is well soluble and stable for weeks in aromatic (benzene, toluene) and for days in etheric (diethyl ether, tetrahydrofuran) solvents at room temperature, in stark contrast to the previously reported $[\mathrm{K}(18-\mathrm{crown}-6)]\left[\mathrm{W}(\mathrm{CO})_{5}(\mathrm{SCP})\right]$. $^{[12]}$ It is also slightly soluble and very stable in aliphatic solvents $(n-$ pentane, $n$-hexane), and decomposes only very slowly (over days of refluxing at $45^{\circ} \mathrm{C}$ ) in dichloromethane to reform the halide complex 1-Cl (Figure S10) and intractable, insoluble precipitates. Having uncovered a clean reaction for the $[\mathrm{SCP}]^{-}$anion, we also sought to synthesize the corresponding thiocyanate and azide complexes, $\mathbf{3}$ and $\mathbf{4}$, in order to assess the influence of the charge distribution of the heterocumulene anion on its binding mode at lanthanum(III). Although the highest negative charge density is mainly located on the terminal atoms of the $[\mathrm{SCN}]^{-}$anion (natural bond orbital atomic charges correspond to -0.47 for $\mathrm{S}$, for $0.06 \mathrm{C}$ and -0.59 for $\mathrm{N}$ ), ${ }^{[13]}$ in stark contrast to the $[\mathrm{SCP}]^{-}$anion (vide infra), we considered 3 to be the adequate reference compound for this purpose. To also study a trinuclear anion with a more evenly distributed charge density, we synthesized the azide complex 4. Complexes 3 and 4 were both obtained by salt metathesis from 1-I and $\mathrm{KSCN}$ (1.2 equiv) or $\mathrm{KN}_{3}$ (1.5 equiv) in THF at room temperature overnight and isolated in $62 \%$ yield (for 3) and $82 \%$ crude yield (for 4$).{ }^{[18]}$ Besides a minor shift of the $P N$ ligand singlet resonance in the ${ }^{31} \mathrm{P}\left\{{ }^{1} \mathrm{H}\right\}$ NMR spectrum $\left(\mathrm{C}_{6} \mathrm{D}_{6}\right)$ from $\delta=9.9 \mathrm{ppm}$ for $1-\mathrm{I}$ to $\delta=10.1 \mathrm{ppm}$ for $\mathbf{3}$ as well as a new broad

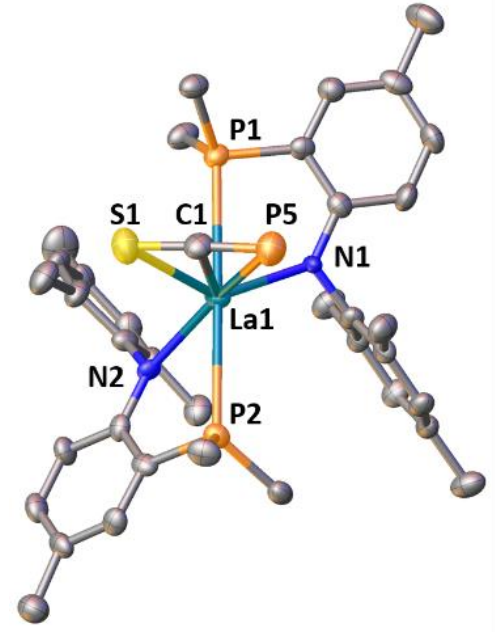

Figure 1. Thermal ellipsoid plot of complex 2. Thermal ellipsoids are shown at a probability level of $50 \%$. Hydrogen atoms have been omitted and $\operatorname{Pr}$ groups truncated for clarity.

singlet resonance at $\delta=142.6 \mathrm{ppm}$ in the ${ }^{13} \mathrm{C}\left\{{ }^{1} \mathrm{H}\right\}$ NMR spectrum, a dominant absorption band in the IR spectrum at $v=2008 \mathrm{~cm}^{-1}$ most clearly indicated the successful coordination of thiocyanate..$^{[19]}$ Similarly, the successful coordination of the azide anion in complex 4 was inferred from a shift of the PN ligand resonance in the ${ }^{31} \mathrm{P}\left\{{ }^{1} \mathrm{H}\right\}$ NMR spectrum $\left(\mathrm{C}_{6} \mathrm{D}_{6}\right)$ to $\delta=5.1 \mathrm{ppm}$ and a strong IR absorption band at $v=2113 \mathrm{~cm}^{-1}$. ${ }^{20]}$

X-ray quality crystals of complex 2 could be grown by slow evaporation of a concentrated toluene solution at room temperature (Figure 1). To our great surprise, we found that the [SCP] $]^{-}$anion is neither solely S- nor P-coordinated, but instead is bound in a side-on $\eta^{3}$-fashion, which is a hitherto unprecedented coordination mode for the family of [ChCPn] ${ }^{-}$anions. Although this was unexpected, considering the fact that most of the negative charge density is located on the central carbon atom of a linear $[\mathrm{S}=\mathrm{C}=\mathrm{P}]^{-}$unit, ${ }^{[13]}$ the participation of all three atoms in the coordination to a strongly Lewis-acidic metal ion such as lanthanum(III) can be reasonably rationalized. In fact, significant coordination of the central carbon atom to lanthanum(III) is evident by comparing the La1-S1, La1-C1 and La1-P5 distances which lie at 3.036(2), 2.837(7) and 3.343(2) $\AA$, respectively. However, these values also show that the [SCP]- anion is not completely symmetrically bound to lanthanum(III) in the solid state. The bond lengths within the [SCP]- anion are 1.607(7) and 1.568(7) $\AA$ for S1-C1 and C1-P5, respectively, resembling the values which are reported for the free $[S C P]^{-}$anion $(S-C$ 1.613(4) $\AA$ and C-P 1.579(4) A). ${ }^{[12,13]}$ The S1-C1-P5 angle of $175.4(5)^{\circ}$ in complex 2 is slightly more acute compared to $179.3(3)^{\circ}$ in the free anion. X-ray quality crystals of reference compounds $\mathbf{3}$ and $\mathbf{4}$ were obtained either by gas diffusion of $n$ hexane into a $\mathrm{C}_{6} \mathrm{D}_{6}$ solution of $\mathbf{3}$ at room temperature overnight or by storing a concentrated toluene extract of 4 at room temperature for $24 \mathrm{~h}$. In contrast to the [SCP]- anion, in both reference complexes, the thiocyanate and the azide anions do not engage in side-on coordination, but instead show a 1,3-bridging coordination mode in the solid state (see Figure S49). In this context, the dinuclear structures of $\mathbf{3}$ and $\mathbf{4}$ strongly suggest that the unique binding mode of the [SCP] $]^{-}$anion in $\mathbf{2}$ is not enforced 


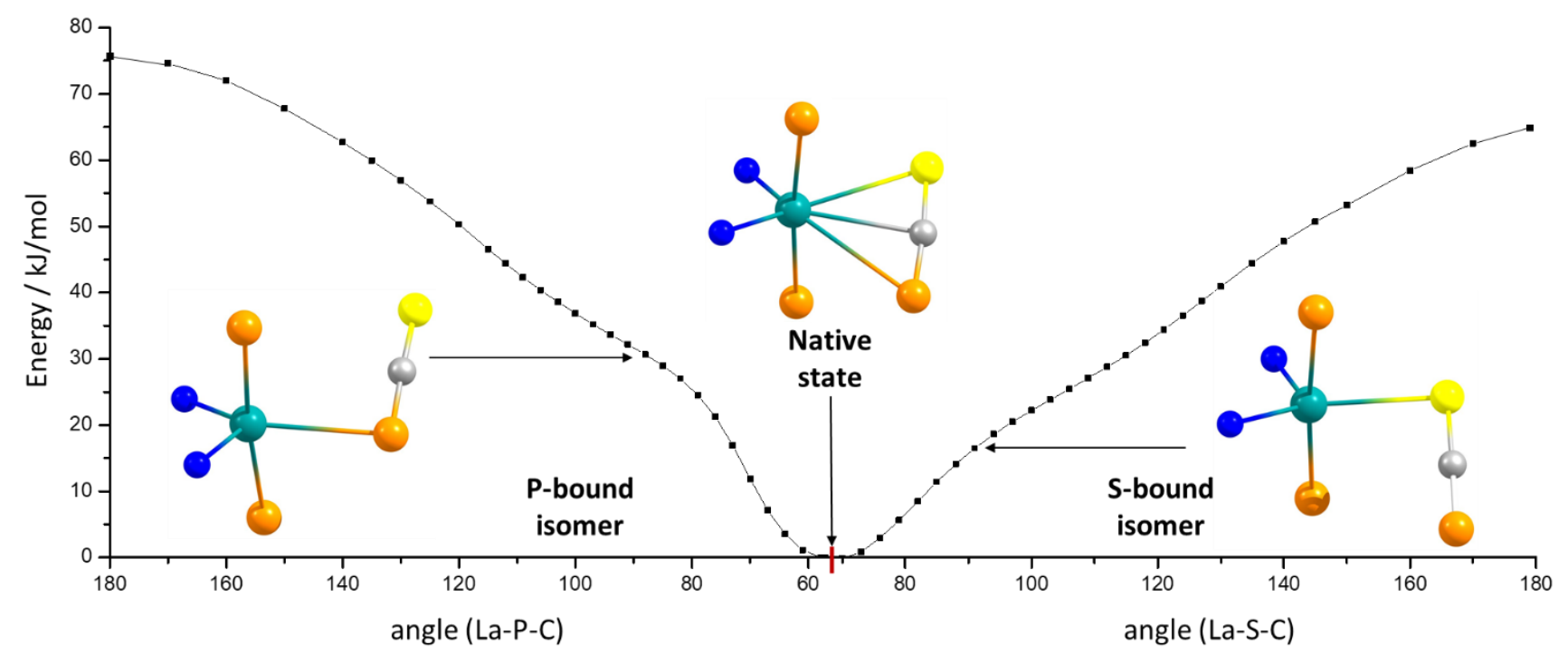

Figure 2. Relative energies of differently bound [SCP $]^{-}$coordination isomers (P-vs S-bound) compared to the side-on $\eta^{3}$-coordinated [SCP] ${ }^{-}$anion, depending on the $\mathrm{La}-\mathrm{E}-\mathrm{C}(\mathrm{E}=\mathrm{P}$ or $\mathrm{S})$ bond angles. The PN supporting ligands have been truncated for clarity.
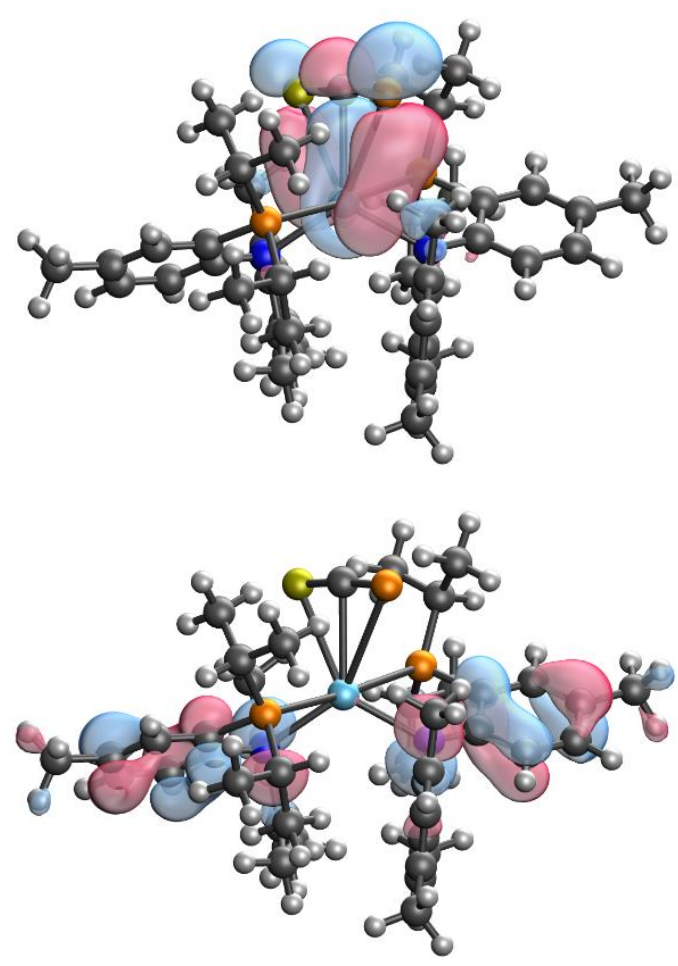

Figure 3. Frontier orbitals (HOMO, bottom; and LUMO, top) of complex 2. Note that the LUMO of complex 2 reflects the bonding interaction of a $\pi^{*}$-orbital of the $[\mathrm{SCP}]^{-}$ligand with the matching d-orbital of the lanthanum(III) center.

by potentially unfavorable steric interactions hindering a 1,3bridging motif, but rather results from the distinctive electronic structure of 2-phosphaethynthiolate, i.e. the significant localization of negative charge density at the carbon atom (vide supra). ${ }^{[13]}$

To gain further insights into the reasons for the stability of the unexpected side-on $\eta^{3}$-coordination mode of the [SCP]-ligand, we investigated complex 2 by means of density functional theory ${ }^{[21]}$ with functionals $\mathrm{PBE}^{[22]}$ and $\mathrm{PBE} 0^{[23]}$ together with def2-SV $(\mathrm{P})$ bases; ${ }^{[24]}$ for details concerning the calculations see the supplementary information (Section 5). Structural optimization of the complex reproduced the values of the $\mathrm{X}$-ray structure very well. The $\mathrm{La}-\mathrm{E}-\mathrm{C}$ angles differ by less than $\sim 2^{\circ}$ from the crystallographically determined numbers of $57.8(3)^{\circ}$ (for $E=P$ ) and $67.4(2)^{\circ}$ (for $E=S$ ). The total interaction energy between $[\mathrm{SCP}]^{-}$and the cationic moiety amounts to $523 \mathrm{~kJ} \cdot \mathrm{mol}^{-1}$, calculated as energy difference without structure relaxation for the fragments. The interaction is mainly ionic, as is evident from the indicators for covalent bonds being very small. For the sum of the contacts S-La, C-La and P-La, the Mullikan overlap population ${ }^{[25]}$ is 0.01 , and the shared electron number ${ }^{[26]}$ is 0.12 . Next, we calculated the change in bond energy for other values of the La-E-C bond angle (and optimized values for the other parameters, see Figure 2 and Tables S3 and S4). An increase of $\sim 15-20^{\circ}$ from the optimum structure already result in a rise of energy by $\sim 20 \mathrm{~kJ} \cdot \mathrm{mol}^{-1}$. Further scanning along the La-E-C angles reveals that the energies reach a maximum at $65 \mathrm{~kJ} \mathrm{~mol}^{-1}$ and $75 \mathrm{~kJ} \cdot \mathrm{mol}^{-1}$ for a linearly S-bound and P-bound isomer of complex 2 , respectively. This is not too surprising, as the overall distance of [SCP] $^{-}$anion to the cation is larger for these configurations, and thus the ionic interaction is smaller. For clarity we note that for none of the structures shown in Figure 2 significant covalent interactions between [SCP] $]^{-}$anion and the cation are observed. More strikingly however, for the $\eta^{3}$. coordination mode of [SCP]- ligand the LUMO of 2 corresponds to the antibonding [SCP] $^{-} \pi$-orbital (Figure 3, top) with a significant admixture of the matching $\mathrm{La}(\mathrm{d})$ orbital (Mulliken contribution ca. 35\%). This should render complex 2 to be an ideal candidate to study the reactivity of the $\left[^{S C P}\right]^{-}$anion towards nucleophiles.

Since cyclic alkyl amino carbenes (CAACs) are generally known for their ability to stabilize highly reactive, exotic structural motifs of main group elements, ${ }^{[27]}$ we decided to focus our efforts on this class of carbenes to achieve a potential functionalization of the $[\mathrm{SCP}]^{-}$ligand. Indeed, when the sterically encumbering ${ }^{A d} \mathrm{CAAC}$ was employed, a highly selective reaction with 2 in aromatic (benzene, toluene) and aliphatic ( $n$-pentane, $n$-hexane) solvents 


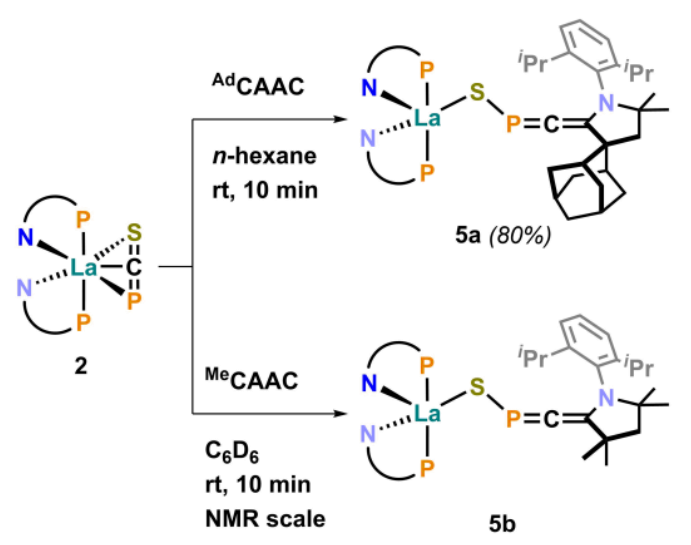

Scheme 2. Reactivity of Complex 2 Towards CAACs to Yield the "Fulminate" Complexes $\mathbf{5 a}$ and $\mathbf{5 b}$.

was observed at room temperature (Scheme 2). Independent of the chosen solvent, the initially yellow reaction mixture immediately turned dark red upon addition of the CAAC (1 eq.), but quickly returned to pale yellow again (within seconds after the addition). Already within 10 min complex 2 was converted to a single, well-defined product, as judged by the ${ }^{31} \mathrm{P}\left\{{ }^{1} \mathrm{H}\right\} \mathrm{NMR}$ spectrum of the crude reaction mixture. Intriguingly, the singlet of the former $[\mathrm{SCP}]^{-}$ligand shifted from $\delta=-44.9 \mathrm{ppm}$ for 2 to $\delta=139.4$ ppm for $\mathbf{5 a}$, indicating a major change of the electronic situation around the phosphorus atom. Product 5 a could be obtained in $80 \%$ isolated yield by crystallization from a concentrated $n$-hexane reaction solution (vide infra). Along with the dramatic low-field shift of the ${ }^{31} \mathrm{P}$ resonance, the ${ }^{13} \mathrm{C}\left\{{ }^{1} \mathrm{H}\right\}$ NMR spectrum $\left(\mathrm{C}_{6} \mathrm{D}_{6}\right)$ of the isolated material showed that the ${ }^{13} \mathrm{C}$ resonance of the former [SCP] ${ }^{-}$unit also shifted significantly to lower fields from $\delta=191.8 \mathrm{ppm}$ for 2 to $\delta=237.3 \mathrm{ppm}$ for $\mathbf{5 a}$. A doublet splitting of this resonance with a larger coupling constant $\left({ }^{1} J_{\mathrm{CP}}=34.9 \mathrm{~Hz}\right.$ for $5 \mathrm{a}$ compared to ${ }^{1} J_{\mathrm{CP}}=20.6 \mathrm{~Hz}$ for 2) suggested that the phosphorus atom of the newly formed ligand in 5a remained bound to the carbon atom, possibly with a stronger electronic interaction than in 2. Importantly, no typical $C_{\text {carbene }}$ resonance above $\delta=200 \mathrm{ppm}$ could be detected in the ${ }^{13} \mathrm{C}\left\{{ }^{1} \mathrm{H}\right\}$ NMR spectrum of $\mathbf{5 a}$. Instead, ${ }^{1} \mathrm{H}-{ }^{13} \mathrm{C}$ HMBC NMR spectroscopic studies of the new compound revealed the former $C_{\text {carbene }}$ of the CAAC moiety to resonate at $\delta=152.2 \mathrm{ppm} \quad\left({ }^{2} J_{\mathrm{CP}}=6.1 \mathrm{~Hz}\right)$, indicating a nucleophilic attack of the CAAC at the central carbon atom of the [SCP]- ligand. Notably, this reactivity does not seem to depend on the steric profile of the CAAC, since the less sterically encumbering CAAC 1-(2,6-diisopropylphenyl)-3,3,5,5tetramethyl-pyrrolidin-2-ylidene $\left({ }^{\mathrm{Me}} \mathrm{CAAC}\right.$, Scheme 2, complex 5b) gave comparable results (for details see Figures S34-S44 in the supporting information).

Due to the high solubility of $\mathbf{5 b}$ even in non-polar solvents such as hexamethyldisiloxane (HMDSO), this product could not be crystallized under any conditions tested (see experimental section in the supporting information), but was only obtained as a crude oily solid after complete removal of solvents in vacuo. On the contrary, X-ray quality crystals of 5 a could be grown from a concentrated $n$-hexane solution (vide supra) over three days at room temperature (Figure 4). Strikingly, the connectivity as found in the former [SCP] $]^{-}$ligand has changed to a formally CAAC stabilized "fulminate-like" [CPS] $]^{-}$anion, with the sulfur atom binding $\kappa^{1}$ to lanthanum(III). A closer examination of the bond metrics within the $\left.{ }^{\mathrm{Ad} C A A C-C P S}\right]^{-}$ligand of $\mathbf{5 a}$ suggests a $\mathrm{C}_{\mathrm{CAAC}}=\mathrm{C}=\mathrm{P}-\mathrm{S}^{-}$heteroallene structure $(\mathrm{C} 100-\mathrm{C} 11.36(2) \AA$; $\mathrm{C} 1-$

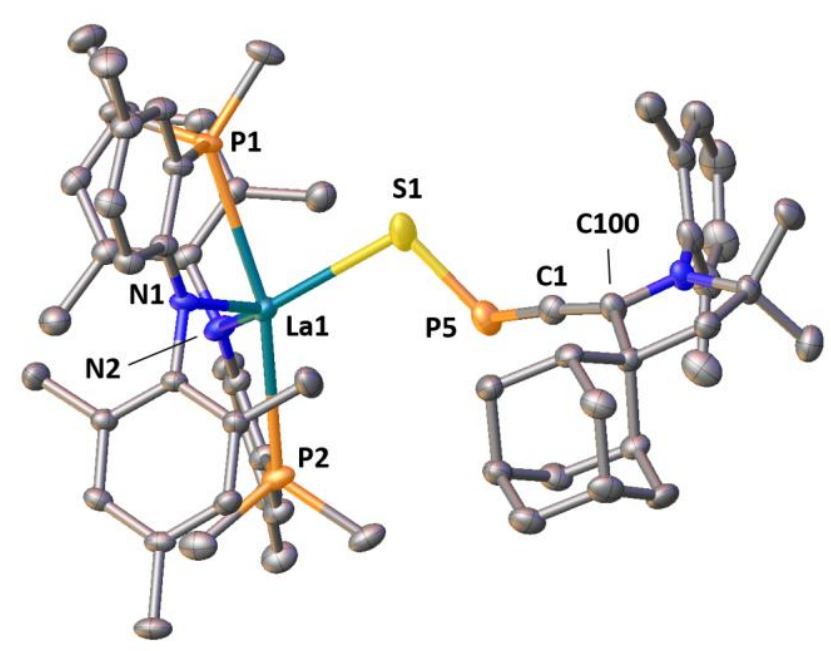

Figure 4. Thermal ellipsoid plot of complex 5a. Thermal ellipsoids are shown at a probability level of $50 \%$. Hydrogen atoms have been omitted and $\mathrm{Pr}$ groups truncated for clarity.

P5 1.63(2) $\AA$ ). While the $C_{C A A C}=C=P$ unit is almost linear $(C 100$ C1-P5 $\left.173.8(1)^{\circ}\right)$, the angle around the phosphorus atom is strongly bent $\left(\mathrm{C} 1-\mathrm{P} 5-\mathrm{S} 1111.1(5)^{\circ}\right)$. The La1-S1 distance was found to be 2.950 (2) $\AA$ and is slightly longer compared to a reported lanthanum - sulfur single bond with the same supporting ligand $(2.718(1) \AA),{ }^{[15]}$ indicating a reduced negative charge on the sulfur atom and a potential partial conjugation of the $\mathrm{C}_{\mathrm{CAAC}}=\mathrm{C}=\mathrm{P}$ unit with the $\mathrm{P}-\mathrm{S}$ bond. This would be in line with the P5-S1 bond length of 2.081(3) $\AA$, which lies in between the values for a $\mathrm{S}=\mathrm{P}$ double $(\approx 1.95 \AA)^{[28]}$ and $\mathrm{S}-\mathrm{P}$ single bond $(\approx 2.12 \AA) .{ }^{[29]}$ Notably, a phosphaalkene thioether has recently been reported by Jones and Kollmann, ${ }^{[30]}$ showing a S-P bond length $(2.095(1) \AA)$ comparable to the one determined in 5a. Additionally, the solid state structure of 5 a reveals a close contact between the CPS phosphorus atom and one of the Dipp- $\mathrm{CH}_{3}$ substituents of the formal ${ }^{A d} C A A C$ unit ( $P \cdots C$ distance of $\approx 3.682 \AA$ ). The retention of this close contact in solution can be inferred from a strong cross correlation peak between the corresponding Dipp- $\mathrm{CH}_{3}$ protons and the CPS phosphorus atom at $\delta=1.36 / 139.3 \mathrm{ppm}$ in the ${ }^{1} \mathrm{H}-{ }^{31} \mathrm{P}$ HMBC NMR spectrum of $\mathbf{5 a}$ (Figure S33). Furthermore, in the ${ }^{13} \mathrm{C}\left\{{ }^{1} \mathrm{H}\right\}$ NMR spectrum a doublet splitting of the corresponding methyl resonance at $\delta=27.0 \mathrm{ppm}\left({ }^{\mathrm{TS}} J_{\mathrm{CP}}=9.8 \mathrm{~Hz}\right.$ ) gives further evidence for a through space interaction. Similar interactions have been previously shown to be harbingers of intriguing reactivity. ${ }^{[31]}$ Finally, in contrast to the IR spectrum of 2, complex 5a shows a distinct strong absorption band at $v=1674 \mathrm{~cm}^{-1}$, which will serve as an useful indicator for the $\mathrm{C}=\mathrm{C}=\mathrm{P}-\mathrm{S}^{-}$structural motif of similar systems in the future.

For a better understanding of the SCP to CPS rearrangement, the reaction pathway from 2 and ${ }^{A d} C A A C$ to 5 a was optimized as specified in detail in the supporting information. The results are shown in Figure 5, with the stationary points (black circles) being fully optimized. Structures II - IV are local minima (no imaginary frequencies); for the two transition structures, which are ca. 50 $\mathrm{kJ} \cdot \mathrm{mol}^{-1}$ higher in energy than the initial structure I, the imaginary frequencies amount to $166 \mathrm{i} \mathrm{cm}^{-1}$ and $244 \mathrm{i} \mathrm{cm}^{-1}$. Finally, the pathways between the stationary points were optimized by a nudged-elastic-band-type procedure proposed by Plessow. ${ }^{[32]}$ The initial step is the nucleophilic attack of the CAAC at the central carbon atom of the SCP unit, leading to structure II, a thio- 


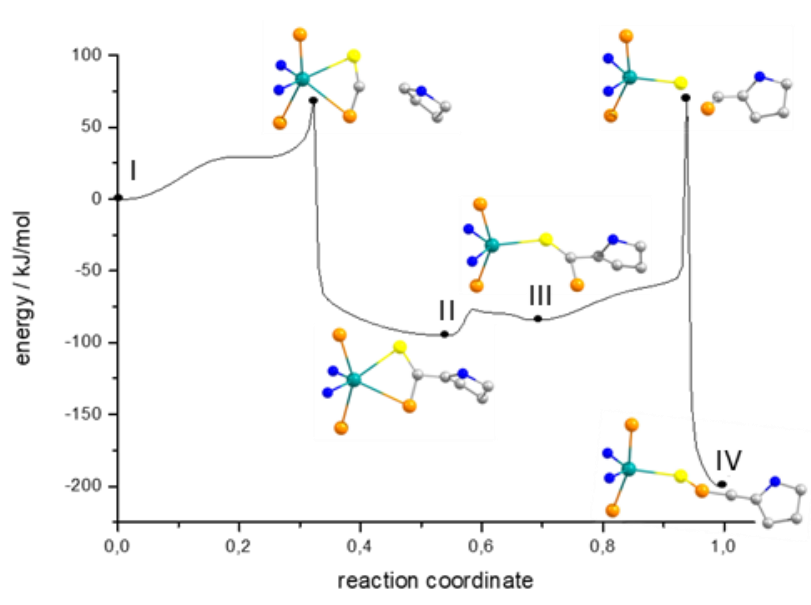

Figure 5. Optimized reaction pathway for the formation of 5 a out of 2 and ${ }^{A d}$ CAAC. Stationary points (black circles) are fully optimized; imaginary frequencies: TS1: $166 \mathrm{i} \mathrm{cm}-1$, TS2: $244 \mathrm{icm}^{-1}$. The pathways between the stationary points are optimized by a nudged-elastic-band-type procedure. The $\mathrm{PN}$ ligands and the ${ }^{\mathrm{Ad} C A A C}$ fragment have been truncated for clarity.

carboxphosphide (a heavy analogue of a carboxamide). A barrier of ca. $70 \mathrm{~kJ} \mathrm{~mol}^{-1}$ needs to be overcome to reach this intermediate structure, which is lower in energy by ca. $100 \mathrm{~kJ} \cdot \mathrm{mol}^{-1}$ compared to structure I. Proceeding along the reaction coordinate, the next step is the dissociation of the phosphorous atom from the lanthanum(III) center, leading to structure III, which is higher in energy by ca. $20 \mathrm{~kJ} \cdot \mathrm{mol}^{-1}$ than structure II and can be reached without a significant barrier. For the ultimate "flip" of the CP unit to form the CPS fulminate anion (structure IV) another transition state must be passed, which is as high in energy as the first one. We note in passing that for this transition structure the covalent interactions between $\mathrm{S}$ and $\mathrm{P}$ or $\mathrm{C}$ are very weak, with shared electron numbers ${ }^{[26]}$ of $\mathrm{ca}$. 0.1 between $S$ and the other two atoms; the two units are held together rather by ionic interactions between the negatively charged $S$ and the positively charged $P$ atom, as worked out in detail in the supplementary information (Figure S52). The formation of a thermodynamically favored P-S bond might be one of the driving forces of this unusual rearrangement reaction with an overall energy gain of ca. $200 \mathrm{~kJ} \cdot \mathrm{mol}^{-1}$. The experimental observation that upon addition of the CAAC the reaction mixture initially turns dark red, before brightening up to a yellow color within the first 30 seconds of the reaction, is in line with the calculated electronic excitation spectra (Figure S51). The lowest-energy excitations for the product (structure IV) are at $2.8 \mathrm{eV}$, for the starting material (structure I) at $2.6 \mathrm{eV}$, but at only $2.2 \mathrm{eV}$ for the "thio-carboxphosphide-type" intermediate structure II. Moreover, the character of the excitation for structure II is of a very different form compared to that of the other structures, see Figure S51. Similar carbene-induced rearrangements of the [OCP] $]^{-}$anion to "fulminate-like" structural motifs have been described by Grützmacher ${ }^{[33,34]}$ and Goicoechea $^{[6]}$ and co-workers for systems based on phosphorus, ${ }^{[33]}$ silicon ${ }^{[34]}$ and boron. ${ }^{[6]}$ With the synthesis of complexes $\mathbf{5 a}$ and $\mathbf{5 b}$ we could extend this type of isomerization chemistry to a f-block metal-based system, yielding the first heavier group 15 - group 16 analogue of a substituted "fulminatelike" anion.

\section{Conclusion}

In conclusion, we have presented the first stable coordination of the hitherto unreactive $[\mathrm{SCP}]^{-}$anion to an electropositive lanthanum(III) ion. Strikingly, the [SCP] $]^{-}$anion in complex 2 neither adopts a S- or P-bound end-on coordination mode as might be expected by the end-on coordinated structures typically encountered for other heterocumulene ligands such as, e.g. thiocyanate or azide (complexes 3 and 4). Instead, the [SCP] anion was found to bind in a $\eta^{3}$-coordination fashion, which had been a completely unknown coordination behavior for such (heavy) heterocumulene anions up to this point. Despite the interactions between the lanthanum(III) complex fragment and the $[\mathrm{SCP}]^{-}$anion being mostly ionic, theoretical calculations revealed the LUMO of complex 2 to correspond mainly to a linear combination of the antibonding $\pi$-orbital of [SCP] $]^{-}$ligand and the geometrically compatible lanthanum(III) d-orbital. Complex 2 therefore showed a high reactivity towards strongly nucleophilic CAACs, which resulted in the rearrangement and concomitant functionalization of the $[\mathrm{SCP}]^{-}$unit to give formally CAACstabilized heavy fulminate-type anions in the products $\mathbf{5 a , b}$ Future work will be dedicated to further investigate other modes of reactivity of the side-on coordinate [SCP]- anion as well as to explore the synthetic use of the new fulminate-type anions (in, e.g. cycloadditions) and open up new avenues for f-element as well as heavy main group element chemistry.

\section{Acknowledgements}

We are grateful to the Daimler and Benz Foundation, the Fonds der Chemischen Industrie, the Young Academy of the NorthRhine-Westphalian Academy of Sciences, Humanities and the Arts, Paderborn University, the University of Innsbruck, and the University of Marburg for financial support. FT and SM thank the DFG (TA 1357/1-1and MI 2561/1-1) for financial support. We are grateful to the vice rectorate for research of the University of Innsbruck for generous funding of this work. Dr. Hans Egold from the NMR facility of the Paderborn University is kindly acknowledged for helpful discussions. Christiane Gloger and Maria Busse are kindly acknowledged for conducting elemental analyses. Dr. Klaus Hübler from University of Stuttgart is kindly acknowledged for helpful discussions about the reactivity of the $[\mathrm{SCP}]^{-}$anion. Funding from the Deutsche Forschungsgemeinschaft (DFG) is acknowledged by $L B$ and MB (Grant no. BA 4467/6-1).

Finally, SH would like to thank Prof. Dr. G. Becker whose lectures and never-ending passion for chemistry, (chemical) history and support encouraged him to pursue a career in academia.

Keywords: lanthanides $\bullet$ phosphines $\bullet$ cyanates $\bullet$ main-group chemistry $\bullet$ f-elements

[1] J. M. Goicoechea, H. Grützmacher, Angew. Chem. Int. Ed. 2018, 57 16968.

[2] a) R. Suter, Z. Benkő, M. Bispinghoff, H. Grützmacher, Angew. Chem. Int. Ed. 2017, 56, 11226; b) G. Becker, G. Heckmann, K. Hbler, W. Schwarz, Z. Anorg. Allg. Chem. 1995, 621, 34; c) D. W. N. Wilson, A Hinz, J. M. Goicoechea, Angew. Chem. Int. Ed. 2018, 57, 2188; d) T. Krachko, A. W. Ehlers, M. Nieger, M. Lutz, J. C. Slootweg, Angew. Chem. Int. Ed. 2018, 57, 1683; e) M. M. Hansmann, D. A. Ruiz, L. L. Liu, R. 
Jazzar, G. Bertrand, Chem. Sci. 2017, 8, 3720; f) D. Heift, Z. Benkő, H Grützmacher, Angew. Chem. Int. Ed. 2014, 53, 6757.

[3] L. Liu, D. A. Ruiz, D. Munz, G. Bertrand, Chem 2016, 1, 147.

[4] L. N. Grant, D. J. Mindiola, Chem. - Eur. J. 2019, 25, 16171.

[5] a) S. Bestgen, M. Mehta, T. C. Johnstone, P. W. Roesky, J. M. Goicoechea, Chem. - Eur. J. 2020, 26, 9024; b) D. W. N. Wilson, J. Feld, J. M. Goicoechea, Angew. Chem. Int. Ed. 2020; c) D. W. N. Wilson, M. P. Franco, W. K. Myers, J. E. McGrady, J. M. Goicoechea, Chem. Sci. 2020, 11, 862; d) A. M. Tondreau, Z. Benkö, J. R. Harmer, H. Grützmacher, Chem. Sci. 2014, 5, 1545

[6] D. W. N. Wilson, M. Mehta, M. P. Franco, J. E. McGrady, J. M. Goicoechea, Chem. - Eur. J. 2020.

[7] a) L. Liu, D. A. Ruiz, F. Dahcheh, G. Bertrand, R. Suter, A. M. Tondreau, H. Grützmacher, Chem. Sci. 2016, 7, 2335; b) J. M. Kieser, R. J. Gilliard A. L. Rheingold, H. Grützmacher, J. D. Protasiewicz, Chem. Commun. 2017, 53, 5110; c) J. Abbenseth, M. Diefenbach, A. Hinz, L. Alig, C Würtele, J. M. Goicoechea, M. C. Holthausen, S. Schneider, Angew. Chem. Int. Ed. 2019, 58, 10966.

[8] S. Bestgen, Q. Chen, N. H. Rees, J. M. Goicoechea, Dalton Trans. 2018 , 47, 13016.

[9] a) C. Camp, N. Settineri, J. Lefèvre, A. R. Jupp, J. M. Goicoechea, L. Maron, J. Arnold, Chem. Sci. 2015, 6, 6379; b) C. J. Hoerger, F. W. Heinemann, E. Louyriac, L. Maron, H. Grützmacher, K. Meyer, Organometallics 2017, 36, 4351; c) S. Liddle, J. Du, G. Balazs, A Wooles, M. Scheer, Angew. Chem. Int. Ed. 2020; d) R. Magnall, G. Balázs, E. Lu, F. Tuna, A. J. Wooles, M. Scheer, S. T. Liddle, Angew. Chem. Int. Ed. 2019, 58, 10215.

[10] G. Becker, W. Schwarz, N. Seidler, M. Westerhausen, Z. Anorg. Allg. Chem. 1992, 612, 72.

[11] G. Becker, K. Hbler, Z. Anorg. Allg. Chem. 1994, 620, 405.

[12] A. R. Jupp, M. B. Geeson, J. E. McGrady, J. M. Goicoechea, Eur. J. Inorg Chem. 2016, 2016, 639.

[13] F. Tambornino, A. Hinz, R. Köppe, J. M. Goicoechea, Angew. Chem. Int Ed. 2018, 57, 8230.

[14] a) Q. Yuan, F. Tambornino, A. Hinz, W. T. Borden, J. M. Goicoechea, B. Chen, X.-B. Wang, Angew. Chem. Int. Ed. 2019, 58, 15062; b) G.-L. Hou, B. Chen, W. J. Transue, Z. Yang, H. Grützmacher, M. Driess, C. C Cummins, W. T. Borden, X.-B. Wang, J. Am. Chem. Soc. 2017, 139 8922.

[15] F. A. Watt, A. Krishna, G. Golovanov, H. Ott, R. Schoch, C. Wölper, A. G. Neuba, S. Hohloch, Inorg. Chem. 2020, 59, 2719.

[16] F. A. Watt, N. Dickmann, R. Schoch, S. Hohloch, Inorg. Chem. 2020, 59 , 13621.

[17] F. A. Watt, K. N. McCabe, R. Schoch, L. Maron, S. Hohloch, Chem. Commun. 2020.

[18] Please note that we only give crude yields for complex 4 as it easily decomposes upon drying to form intractable mixtures.

[19] R. E. Wilson, T. J. Carter, M. Autillo, S. Stegman, Chem. Commun. 2020 , 56, 2622.

[20] a) M. A. Boreen, G. Rao, D. G. Villarreal, F. A. Watt, R. D. Britt, S. Hohloch, J. Arnold, Chem. Commun. 2020, 56, 4535; b) T. A. Bazhenova V. S. Mironov, I. A. Yakushev, R. D. Svetogorov, O. V. Maximova, Y. V. Manakin, A. B. Kornev, A. N. Vasiliev, E. B. Yagubskii, Inorganic chemistry 2020, 59, 563; c) Xiao-Lei Li, Jianfeng Wu, Lang Zhao, Wei Shi, Peng Cheng, Jinkui Tang, Chem. Commun. 2017, 53, 3026.

[21] TURBOMOLE V7.5 2020, a development of University of Karlsruhe and Forschungszentrum Karlsruhe $\mathrm{GmbH}$, 1989-2007, TURBOMOLE GmbH, since 2007, available from http://www.turbomole.com.

[22] Perdew, Burke, Ernzerhof, Phys. Rev. Lett. 1996, 77, 3865

[23] J. P. Perdew, M. Ernzerhof, K. Burke, J. Chem. Phys. 1996, 105, 9982.

[24] F. Weigend, R. Ahlrichs, Phys. Chem. Chem. Phys. 2005, 7, 3297.

[25] R. S. Mulliken, J. Chem. Phys. 1955, 23, 1833.

[26] R. Heinzmann, R. Ahlrichs, Theor. Chim. Acta 1976, 42, 33

[27] a) M. Melaimi, R. Jazzar, M. Soleilhavoup, G. Bertrand, Angew. Chem. Int. Ed. 2017, 56, 10046; b) M. Soleilhavoup, G. Bertrand, Acc. Chem. Res. 2015, 48, 256.

[28] S. R. Daly, J. R. Klaehn, K. S. Boland, S. A. Kozimor, M. M. Maclnnes, D. R. Peterman, B. L. Scott, Dalton Trans. 2012, 41, 2163.
[29] N. Burford, B. W. Royan, P. S. White, Acta Crystallogr C Cryst Struct Commun 1990, 46, 274

[30] P. G. Jones, R. Bîrzoi, W.-W. Du Mont, S. Kollmann, CCDC 1055259 : Experimental Crystal Structure Determination, Cambridge Crystallographic Data Centre, 2015.

[31] M. E. Garner, B. F. Parker, S. Hohloch, R. G. Bergman, J. Arnold, J. Am. Chem. Soc. 2017, 139, 12935.

[32] P. Plessow, J. Chem. Theory and Comput. 2013, 9, 1305.

[33] Z. Li, X. Chen, Z. Benkő, L. Liu, D. A. Ruiz, J. L. Peltier, G. Bertrand, C.Y. Su, H. Grützmacher, Angew. Chem. Int. Ed. 2016, 55, 6018.

[34] Z. Li, X. Chen, Y. Li, C.-Y. Su, H. Grützmacher, Chem. Commun. 2016 $52,11343$. 


\section{Entry for the Table of Contents}

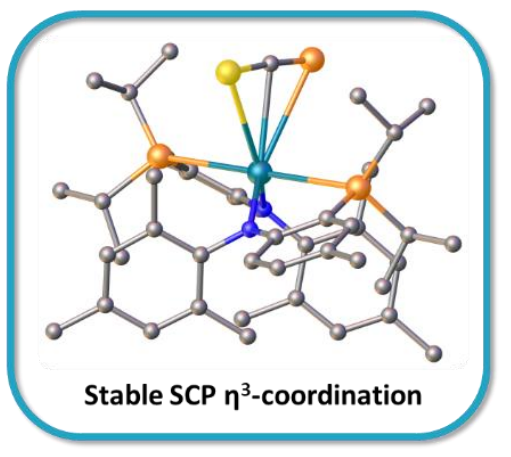

We report the first stable coordination of the 2-phosphaethynthiolate ([SCP] $]^{-}$) anion at a Lewis-acidic lanthanum(III) ion and its subsequent rearrangement to form a heavy "fulminate-like" CPS anion, induced by CAACs.

University of Innsbruck, Twitter: @HohlochL 